\title{
SUPREMO TRIBUNAL FEDERAL NO PERÍODO DA PANDEMIA COVID-19: AMBIENTE VIRTUAL COMO UMA SOLUÇÃO DE EFICIÊNCIA JURISDICIONAL E AMPLIAÇÃO DO DIREITO DE ACESSO À JUSTIÇA
}

\author{
Alexandre Reis Siqueira Freire ${ }^{1}$ \\ Thiago Gontijo Vieira ${ }^{2}$
}

\begin{abstract}
Resumo: Este artigo analisa as políticas públicas adotadas pelo STF no período da Covid-19, com o recorte temático do ambiente virtual de julgamento. O objetivo é investigar se os julgamentos assíncronos contribuíram para a eficiência da prestação jurisdicional e a promoção do direito de acesso à justiça. A metodologia foi a empírica-indutiva, com a análise dos regulamentos da Corte e o estudo de dados estatísticos. O resultado foi a sistematização do desenho deliberativo virtual da Corte e a demonstração de sua importância para a efetiva prestação jurisdicional. Pretende-se estimular estudos para a criação de um modelo de cortes on-line.
\end{abstract}

Palavras-chave: Supremo Tribunal Federal; Covid-19; Julgamentos Virtuais; Responsabilidade Institucional; Eficiência; Direito de Acesso à justiça.

\section{BRAZILIAN FEDERAL SUPREME COURT DURING THE COVID-19 PANDEMIC PERIOD: VIRTUAL ENVIRONMENT AS A SOLUTION OF JURISDICTIONAL EFFICIENCY AND ENLARGEMENT OF THE RIGHT OF ACCESS TO JUSTICE}

\begin{abstract}
This study analyzes the judicial policies adopted by the Brazilian Federal Supreme Court in the Covid-19 period, from the thematic of the virtual trial environment. The objective is to determine if the asynchronous judgments contributed to the efficiency of the judicial system and to the promotion of the right of Access to Justice. It used the empirical-inductive methodology, organizing the STF's regulations and studying statistical data. The result was the systematization of the virtual environment design of the Court and the demonstration of its importance to the effectiveness of the jurisdiction. It aims to stimulate studies for the creation of an online courts model.
\end{abstract}

Keywords: Brazilian Federal Supreme Court; Covid-19; Virtual Trials; Accountability; Efficiency; Right of Access to Justice.

\footnotetext{
${ }^{1}$ Doutor em Direito pela Pontifícia Universidade Católica de São Paulo (PUC/SP). Mestre em Direito pela Universidade Federal do Paraná (UFPR). Professor da Universidade Nove de Julho (UNINOVE) e da Universidade Federal do Maranhão (UFMA). Secretário de Altos Estudos, Pesquisas e Gestão da Informação do Supremo Tribunal Federal (STF). Endereço postal: Supremo Tribunal Federal, Praça dos Três Poderes, Brasília, DF, Brasil, CEP 70175-900. Endereços eletrônicos: freirealexandre@hotmail.com; e alexandre.freire@stf.jus.br.

2 Mestrando em Direito pela Universidade Nove de Julho (UNINOVE). Graduado em Direito pelo Centro Universitário de Brasília (UniCEUB). Especialista em Direito Tributário pelo Instituto Brasileiro de Estudos Tributários (IBET). Professor seminarista do IBET. Analista Judiciário e Coordenador de Difusão da Informação do Supremo Tribunal Federal (STF). Endereço postal: Supremo Tribunal Federal, Praça dos Três Poderes, Brasília, DF, Brasil, CEP 70175-900. Endereços eletrônicos: thiago.gontijo@yahoo.com; e thiago.gontijo@stf.jus.br.
} 


\section{Introdução}

No Brasil, a pandemia da Covid-19 tem produzido múltiplos efeitos nas competências e atribuições das instituições estatais em todos os entes federados e nas diferentes esferas do Poder. Nesse contexto, o Poder Judiciário passou a receber um elevado volume de processos relacionados ao novo coronavírus. Diante desse cenário de desafio, os atores do Estado adotaram diversas políticas públicas para conter a expansão do vírus e mitigar os seus danos.

No plano global, em 30/1/2020, a Organização Mundial da Saúde (OMS) proferiu declaração de emergência em saúde pública de importância internacional. Em 11/3/2020, a doença causada pelo novo coronavírus (Sars-Cov-2) foi classificada como pandemia, e o vírus passou a ser considerado pela OMS como de transmissão e disseminação global.

No âmbito federal, em janeiro de 2020, o Comitê de Monitoramento de Eventos do Ministério da Saúde publicou o primeiro boletim epidemiológico com informações sobre a doença. Ainda nesse mês, ocorreu a ativação do Centro de Operações de Emergências em Saúde Pública para o novo Coronavírus (COE-nCoV). O primeiro caso de Covid-19 no Brasil foi detectado na cidade de São Paulo em 26/2/2020.

A situação de emergência de saúde pública de importância nacional (ESPIN) foi declarada pelo governo federal em 3/2/2020. Na sequência, foi editada a Lei $n^{\circ} 13.979 / 2020^{3}$, que prevê diversas medidas para enfrentamento da emergência de saúde pública decorrente do coronavírus, tais como isolamento; quarentena; determinação de realização compulsória de exames, uso obrigatório de máscaras de proteção individual, entre outras.

Diversas outras políticas de saúde pública, administrativas e normativas, foram adotadas pelos Poderes Executivo, Legislativo e Judiciário de praticamente todos os entes da Federação - senão todos -, com o objetivo de evitar a disseminação do vírus e amenizar o agravamento de seus efeitos.

A partir desse contexto, o Supremo Tribunal Federal (STF) foi o único tribunal do Brasil que manteve o seu funcionamento durante todo o período da pandemia, sem suspensão

\footnotetext{
3 BRASIL. LEI $n^{0}$ 13.979, de 6 de fevereiro de 2020. Dispõe sobre as medidas para enfrentamento da emergência de saúde pública de importância internacional decorrente do coronavírus responsável pelo surto de 2019. Disponível em: http://www.planalto.gov.br/ccivil_03/_ato2019-2022/2020/lei/113979.htm. Acesso em: 16 fev. 2021. Foram publicadas ainda outras alterações normativas subsequentes, por meio de medidas provisórias que foram convertidas nas Leis 14.006, 14.019 e 14.035, todas de 2020.
} 


\section{SUPREMO TRIBUNAL FEDERAL NO PERÍODO DA PANDEMIA COVID-19: AMBIENTE VIRTUAL \\ COMO UMA SOLUÇÃO DE EFICIÊNCIA JURISDICIONAL E AMPLIAÇÃO DO \\ DIREITO DE ACESSO À JUSTIÇA}

geral de prazos processuais, como determinado pelo Conselho Nacional de Justiça ${ }^{4}$ aos demais tribunais e juízos brasileiros.

Desde então, a Corte Suprema passou a apreciar milhares de processos relacionados ao novo coronavírus, tanto em questões individuais quanto em temáticas de interesse coletivo de toda a sociedade brasileira. Sem prejuízo das demais matérias, o julgamento das demandas relacionadas à Covid-19 foi priorizado pelo Tribunal, que adotou mecanismos de monitoramento e pauta prioritária para uma resposta rápida e efetiva à sociedade, sob pena de perecimento de direitos fundamentais ou de desvirtuamento das competências e atribuições delineadas na Constituição da República.

Diante do impacto e da relevância desse momento de crise, este artigo propõe-se a analisar as políticas públicas judiciárias adotadas pelo STF no período da Covid-19, com o recorte temático do ambiente virtual de julgamento colegiado. $\mathrm{O}$ objetivo principal é investigar se esse espaço assíncrono de deliberação contribuiu para a eficiência da prestação jurisdicional e para a promoção do direito de acesso à justiça. Como objetivo específico, será avaliado se o sistema virtualizado dispõe de soluções que assegurem o exercício dos princípios constitucionais do devido processo legal e da ampla defesa.

A metodologia utilizada foi a empírica-indutiva, por meio da análise e sistematização das medidas administrativas e normas regimentais e regulamentares relacionadas aos objetos da pesquisa, bem como pelo estudo quantitativo de dados estatísticos apresentados em relatórios de atividades e em painéis gerenciais de transparência jurisdicional.

Como resultados, busca-se elucidar o desenho deliberativo atual do ambiente virtual de julgamento e o seu papel na efetiva prestação jurisdicional do Tribunal. Pretende-se ainda estimular a produção de estudos científicos acerca de um modelo de Desenho de Julgamento Virtual (DJV) que possa servir como parâmetro para o ecossistema judicial de Cortes on-line no período pós-Covid-19.

\footnotetext{
${ }^{4}$ BRASIL. Conselho Nacional de Justiça. Resolução $\mathbf{n}^{\mathbf{0}}$ 313/2020, de 19 de março de 2020. Estabelece, no âmbito do Poder Judiciário, regime de Plantão Extraordinário, para uniformizar o funcionamento dos serviços judiciários, com o objetivo de prevenir o contágio pelo novo coronavírus - Covid-19, e garantir o acesso à justiça neste período emergencial. Disponível em: https://atos.cnj.jus.br/atos/detalhar/3249. Acesso em: 12 abr. 2021.
} 


\section{STF: políticas públicas judiciárias no período da Covid-19}

Desde o início de março de 2020, o Supremo implementou diversas medidas sanitárias ${ }^{5}$, administrativas $^{6}$ e jurisdicionais ${ }^{7}$ para prevenir o contágio pelo Novo Coronavírus (Covid19) ${ }^{8}$. Foi consolidado um Novo Modelo de Gestão (NMG), com métodos e ferramentas que priorizam o trabalho remoto na administração pública, dispensada a presença de magistrados, servidores e colaboradores nos espaços físicos do Tribunal, salvo para atividades consideradas essenciais e incompatíveis com o trabalho remoto.

No dia 23/3/2020, por meio da Resolução no 670/2020 ${ }^{9}$, novas medidas, ainda mais restritivas, foram estabelecidas, para reduzir a circulação interna de pessoas e o deslocamento laboral, em consonância com as recomendações emitidas pelo Ministério da Saúde a partir da caracterização do Distrito Federal como Área com Transmissão Comunitária ${ }^{10}$.

Nesse regulamento, determinou-se: a suspensão dos prazos processuais de processos físicos; a suspensão de todo o atendimento presencial aos públicos externo e interno - salvo exceções; a realização de todas as atividades do Tribunal na modalidade remota, quando compatíveis; a suspensão de todos os serviços internos não essenciais e que sejam incompatíveis com o trabalho remoto; e a redução do trabalho presencial ao nível mínimo necessário para a manutenção dos serviços internos essenciais incompatíveis com o trabalho remoto.

${ }^{5}$ BRASIL. Supremo Tribunal Federal. Página de monitoramento da Covid-19. Brasília, [2021]. Disponível em: http://portal.stf.jus.br/covid19. Acesso em: 10 abr. 2021. Como exemplos das medidas implementadas, citam-se: realização de testes rápidos de Covid-19; trabalho de vigilância epidemiológica; protocolos sanitários de distanciamento social e higiene; e roda de terapia comunitária integrativa.

${ }^{6}$ Como exemplos das medidas administrativas implementadas, citam-se: ampliação e consolidação do novo modelo de gestão; e implementação do Microsoft Teams.

${ }^{7}$ Como exemplos das medidas jurisdicionais implementadas, citam-se: sessões síncronas por videoconferência; e ampliação e aperfeiçoamento da competência jurisdicional das sessões virtuais.

${ }^{8}$ STF lança site especial sobre ações da Corte no combate à Covid-19. Supremo Tribunal Federal. Brasília, 25 mar. 2021. Disponível em: http://portal.stf.jus.br/noticias/verNoticiaDetalhe.asp?idConteudo=462946\&ori=1. Acesso em: 10 abr. 2021.

${ }^{9}$ BRASIL. Supremo Tribunal Federal. Resolução no 670, de 23 de março de 2020. Estabelece novas medidas temporárias de prevenção ao contágio pelo Novo Coronavírus (Covid-19) no Supremo Tribunal Federal (STF). Disponível em: http://www.stf.jus.br/arquivo/cms/noticiaNoticiaStf/anexo/Resolucao670.pdf. Acesso em: $1^{\circ}$ abr. 2021.

${ }^{10}$ BRASIL. Ministério da Saúde. Centro de Operações de Emergências em Saúde Pública | COE-nCoV. Boletim Epidemiológico $\mathbf{n}^{\mathbf{0}} \mathbf{5}$ de $\mathbf{1 4}$ de março de $\mathbf{2 0 2 0}$. Disponível em: https://proqualis.net/sites/proqualis.net/files/ERRATA\%20\%20Boletim\%20Epidemiol\%C3\%B3gico\%2005.pdf. Acesso em: $1^{\circ}$ abr. 2021. 


\section{SUPREMO TRIBUNAL FEDERAL NO PERÍODO DA PANDEMIA COVID-19: AMBIENTE VIRTUAL COMO UMA SOLUÇÃO DE EFICIÊNCIA JURISDICIONAL E AMPLIAÇÃO DO \\ DIREITO DE ACESSO À JUSTIÇA}

Como regra, o atendimento judicial de partes, advogados, procuradores, defensores e de toda a sociedade passou a ocorrer por meio eletrônico ou telefônico, mantido o atendimento presencial exclusivamente para processos físicos urgentes, assegurado o plantão judicial ${ }^{11}$ aos sábados, domingos e feriados.

Com relação aos processos físicos, foi estabelecido que a suspensão dos prazos processuais não impede a prática de ato processual urgente necessário à preservação de direitos, ficando garantida a apreciação das matérias de competência do STF, tais como medidas liminares e de antecipão de tutela de qualquer natureza.

A partir da Resolução $\mathrm{n}^{\circ} 677^{12}$, novas medidas de médio prazo para a gestão das atividades do Tribunal foram fixadas, igualando o regime de trabalho remoto com o presencial, ambos voltados para uma gestão focada em resultados. O trabalho remoto consolidou-se na Corte e passou a ser a opção de mais de $90 \%$ dos servidores em julho de 2020 - no fim de 2019, o quantitativo era de $15 \% .^{13}$

A predominância de processos em meio eletrônico contribuiu para a virtualização da Corte. De acordo com o Relatório de Atividades $2020^{14}$, “desde 2013, a tramitação eletrônica supera a física. O esforço para a digitalização do acervo, uma das diretrizes estratégicas da Corte, decorre da implementação de novas tecnologias e sistemas de automação. Em 2020, atingiu-se a marca de $96 \%$ de digitalização dos processos".

Como dito, ao se voltar o olhar para a atividade jurisdicional, a Corte foi instada a se manifestar em milhares de processos relacionados à pandemia da Covid-19, tanto em demandas individuais dos cidadãos quanto de interesse coletivo de toda a sociedade brasileira.

Essas demandas exigiam respostas rápidas e efetivas, sob pena de perecimento de direitos fundamentais ou de desvirtuamento das competências e atribuições delineadas na

11 BRASIL. Supremo Tribunal Federal. Resolução no 449, de 2 de dezembro de 2010. Dispõe sobre funcionamento de plantão judiciário. Disponível em: http://www.stf.jus.br/arquivo/norma/resolucao4492010.pdf. Acesso em: 10 abr. 2021.

12 BRASIL. Supremo Tribunal Federal. Resolução no 677, de 29 de abril de 2020. Estabelece medidas de médio prazo para gestão das atividades do Tribunal. Disponível em: http://www.stf.jus.br/arquivo/cms/noticiaNoticiaStf/anexo/Resolucao677.pdf. Acesso em: 10 abr. 2021.

${ }^{13}$ BRASIL. Supremo Tribunal Federal. Relatório da Gestão 2018-2020 (Min. Dias Toffoli). Brasília, 2020, p. 184. Disponível em: http://www.stf.jus.br/arquivo/cms/noticiaNoticiaStf/anexo/relatorioGestao2020.pdf. Acesso em: 10 abr. 2021.

14 BRASIL. Supremo Tribunal Federal. Relatório de atividades 2020. Brasília: Supremo Tribunal Federal, Secretaria de Altos Estudos, Pesquisas e Gestão da Informação, 2021. Disponível em: http://www.stf.jus.br/arquivo/cms/publicacaoCatalogoProdutoConteudoTextual/anexo/RelatorioAtividadesSTF 2020.pdf. Acesso em: 10 abr. 2021. 
Constituição da República. Conforme Relatório da Gestão 2018-2020, “durante o enfrentamento da crise sanitária, a Suprema Corte priorizou o julgamento das questões relativas à pandemia". ${ }^{15}$

Em 2020, com base nos dados do Painel de Ações Covid-19, o Tribunal apreciou um total de 8.765 processos, assim distribuídos conforme o grupo de classe: originários criminais (6.705); demais originários (1.615); controle concentrado (368); e recursais (77). Desde março de 2020, o painel informa a sociedade e viabiliza o acompanhamento das ações perante a Corte relacionadas à pandemia do coronavírus, bem como as decisões tomadas pelo Tribunal sobre o tema. ${ }^{16}$

Para viabilizar o atendimento prioritário a essas demandas, bem como assegurar a manutenção das atividades e o amplo direito de acesso à justiça, o STF implementou soluções de aperfeiçoamento de seus ambientes deliberativos, pelo uso da tecnologia, e garantiu a manutenção da efetiva prestação jurisdicional, mesmo diante do contexto de suspensão de atividades presenciais não essenciais.

\section{Videoconferência nas sessões presenciais}

No contexto da pandemia da Covid-19, em 18/3/2020, na $2^{\text {a }}$ Sessão Administrativa do STF foi decidido, além de outras medidas, que as sessões de julgamento presencial seriam realizadas por meio de videoconferência. Com isso, ministros, advogados e demais atores processuais passaram a participar das sessões sem a necessidade de estarem presentes no espaço físico do Tribunal, como medida essencial de prevenção à Covid-19.

Essa iniciativa está alinhada com a previsão do art. 937, § $4^{\circ}$, do Código de Processo Civil $(\mathrm{CPC})^{17}$, que permite a realização de sustentação oral em sessões de julgamento por

15 BRASIL. Supremo Tribunal Federal. Relatório de atividades 2020. Brasília: Supremo Tribunal Federal, Secretaria de Altos Estudos, Pesquisas e Gestão da Informação, 2021. Disponível em: http://www.stf.jus.br/arquivo/cms/publicacaoCatalogoProdutoConteudoTextual/anexo/RelatorioAtividadesSTF 2020.pdf. Acesso em: 10 abr. 2021.

16 Painel mostra dados atualizados sobre processos relacionados à Covid-19 no STF. Supremo Tribunal Federal. Brasília, 27 mar. $2020 . \quad$ Disponível em: http://portal.stf.jus.br/noticias/verNoticiaDetalhe.asp?idConteudo=440336\&ori=1. Acesso em: 15 abr. 2021.

17 BRASIL. Lei $\mathbf{n}^{\circ}$ 13.105 de 16 de março de 2015. Institui o Código de Processo Civil. Disponível em http://www.planalto.gov.br/ccivil_03/_ato2015-2018/2015/lei/113105.htm. Acesso e 1\%/4/2021: Art. 937. Na sessão de julgamento, depois da exposição da causa pelo relator, o presidente dará a palavra, sucessivamente, ao recorrente, ao recorrido e, nos casos de sua intervenção, ao membro do Ministério Público, pelo prazo improrrogável de 15 (quinze) minutos para cada um, a fim de sustentarem suas razões, nas seguintes hipóteses, nos termos da parte final do caput do art. 1.021: (...). $4^{\circ}$ É permitido ao advogado com domicílio profissional 
meio de videoconferência ou outro recurso tecnológico de transmissão de sons e imagens em tempo real, desde que o advogado o requeira até o dia anterior ao da sessão e tenha domicílio profissional em cidade diversa daquela onde está sediado o tribunal.

Para isso, foi incluída previsão no Regimento Interno da Corte (art. 131, $\S 5^{\text {o18 }}$ ) que assegura o exercício da ampla defesa e do contraditório mesmo de maneira remota, por meio de sustentação oral por videoconferência $\left(E^{\circ} n^{\circ} 53 / 2020^{19}\right)$. As sessões por videoconferência do Plenário e das Turmas estão previstas na Resolução n $n^{\circ} 672 / 2020^{20}$ e são transmitidas ao vivo no canal do STF no YouTube, para acompanhamento por toda a sociedade em tempo real.

Para viabilizar as sessões à distância, o STF utilizou a ferramenta Webex Meetings. ${ }^{21} \mathrm{~A}$ solução foi disponibilizada gratuitamente pelo Conselho Nacional de Justiça (CNJ) aos tribunais e magistrados brasileiros como resultado do Termo de Cooperação Técnica $7 / 2020^{22}$, celebrado com a Cisco Brasil ${ }^{23}$. Essa parceria não implicou nenhum custo ou compromisso financeiro à Justiça e foi encerrada, após duas prorrogações, em 30/1/2021.

Essa colaboração entre o CNJ e uma empresa transnacional, num momento de crise pandêmica global, representa um caso de materialização da teoria do capitalismo humanista ${ }^{24}$, em que o setor privado colaborou com o público na efetivação do princípio constitucional do

em cidade diversa daquela onde está sediado o tribunal realizar sustentação oral por meio de videoconferência ou outro recurso tecnológico de transmissão de sons e imagens em tempo real, desde que o requeira até o dia anterior ao da sessão.

18 BRASIL. Supremo Tribunal Federal. Emenda Regimental $\mathbf{n}^{\mathbf{0}}$ 42, de 2 de dezembro de 2010. Altera dispositivos do Regimento Interno do Supremo Tribunal Federal. Disponível em: http://www.stf.jus.br/arquivo/norma/emendaregimental042-2010.pdf. Acesso em: $1^{\circ}$ abr. 2021.

${ }^{19}$ BRASIL. Supremo Tribunal Federal. Emenda Regimental no 53, de 18 de março de 2020. Altera dispositivo do Regimento Interno do Supremo Tribunal Federal para ampliar as hipóteses de julgamento por meio eletrônico e prever a realização de sustentação oral em ambiente virtual. Disponível em: http://www.stf.jus.br/arquivo/cms/noticiaNoticiaStf/anexo/Emenda53.pdf. Acesso em: 13 abr. 2021.

${ }^{20}$ BRASIL. Supremo Tribunal Federal. Resolução no 672, de 26 de março de 2020. Altera a Resolução nº 642 , de 14 de junho de 2019 e dá outras providências. Disponível em: http://www.stf.jus.br/arquivo/cms/noticiaNoticiaStf/anexo/Resolucao672.pdf. Acesso em: 28 jun. 2021.

${ }^{21}$ BRASIL. Supremo Tribunal Federal. Relatório da Gestão 2018-2020 (Min. Dias Toffoli). Brasília, 2020, p. 184. Disponível em: http://www.stf.jus.br/arquivo/cms/noticiaNoticiaStf/anexo/relatorioGestao2020.pdf. Acesso em: 10 abr. 2021.

${ }^{22}$ BRASIL. Conselho Nacional de Justiça. Termo de Cooperação Técnica $\mathbf{n}^{\mathbf{0}}$ 7/2020. Processo CNJ SEI $n^{\circ}$ 03344/2020. Disponível em: https://www.cnj.jus.br/wp-content/uploads/2020/04/TCOT-007_2020.pdf. Acesso em: 12 abr. 2021.

${ }^{23}$ Witepaper: Caso de sucesso - Conselho Nacional de Justiça (CNJ). Cisco Brasil. Brasília, 2020. Disponível em: https://www.cisco.com/c/dam/global/pt_br/solutions/pdfs/whitepaper-cnj.pdf. Acesso em: 12 abr. 2020.

${ }^{24}$ SAYEG, Ricardo. Fator CAPH - capitalismo humanista: a dimensão econômica dos direitos humanos. São Paulo: Max Limonad, 2019. 
acesso à justiça (art. 5 XXXV, da Constituição Federal). O capitalismo humanista apresenta os fundamentos teóricos do direito econômico humanista, diante da prevalência do capitalismo planetário e, sob essa perspectiva juris-econômica, analisa a incidência multidimensional dos direitos humanos e sua repercussão no direito pátrio.

Essa foi a principal mudança implementada por tribunais brasileiros ${ }^{25}$ e outras cortes constitucionais e tribunais estrangeiros, que avançaram na migração de processos físicos para eletrônicos e implementaram soluções de audiência e julgamento remotos por videoconferência ${ }^{26}$.

Na visão de Richard Susskind, em termos tecnológicos, a realização de sessões por videoconferência é algo antigo, concebido nos anos 1980, e que representa apenas um primeiro passo na transformação das cortes. Para o autor, esses sistemas remotos serão suplantados por procedimentos assíncronos na próxima década, como ambientes on-line de resolução de disputas conectados aos tribunais, telepresença, realidade virtual, blockchain e inteligência artificial. ${ }^{27}$

Entretanto, esse avanço tecnológico deve manter a garantia, por exemplo, de participação de amicus cueriae e a realização de audiência pública, como espaço democrático de legitimidade das decisões formalizadas no incidente de recursos extraordinários repetitivos. $^{28}$

${ }^{25}$ Tribunais devem adotar videoconferência para audiências e atos. Conselho Nacional de Justiça. Brasília, 23 set. 2020. Disponível em: https://www.cnj.jus.br/servicos-por-videoconferencia-serao-mantidos-no-judiciarioapos-a-pandemia. Acesso em: 15 abr. 2021.

${ }^{26}$ Covid-19 pandemic Impact of COVID-19 on Court Operations \& Litigation Practice. IBA Litigation Committee. London, June 22, 2020. Disponível em: https://www.ibanet.org/MediaHandler?id=E9A83AEF6B17-4A54-815F-1C6E0D600163. Acesso em: 15 abr. 2021.

${ }^{27}$ SUSSKIND, Richard. Video hearings have transformed courts but are not a panacea. The Times. London, April 01, 2021. Disponível em: https://www.thetimes.co.uk/article/video-hearings-have-transformed-courtsbut-are-not-a-panacea-mcp77mjj7. Acesso 9 abr. 2021; e KRANS, Bart; NYLUND, Anna. Civil Courts Coping with Covid-19. ISBN Boek: 978-94-6236-204-8, 1e druk. Jaar van uitgave: 2021.

${ }^{28}$ Nas palavras de Alexandre Freire: "A audiência pública visa, entre outros propósitos, ampliar a legitimidade democrática das decisões do Supremo Tribunal Federal, em ações, recursos e incidentes, bem como dirimir questões técnicas e colher colaborações de especialistas a respeito de temáticas multidisciplinares que estão fora do campo de compreensão dos ministros e que, uma vez não esclarecidas por especialistas, podem comprometer a qualidade das razões de decidir que constarão do precedente a ser formado pela Suprema Corte" (FREIRE, Alexandre. O incidente de resolução de recursos extraordinários repetitivos e as audiências públicas no Supremo Tribunal Federal. In: NERY JUNIOR, Nelson; ARRUDA ALVIM, Teresa; MIRANDA DE OLIVEIRA, Pedro. Aspectos polêmicos dos recursos cíveis e assuntos afins. v. 14. São Paulo: RT, 21-57, 2018. p. 43). 


\section{SUPREMO TRIBUNAL FEDERAL NO PERÍODO DA PANDEMIA COVID-19: AMBIENTE VIRTUAL \\ COMO UMA SOLUÇÃO DE EFICIÊNCIA JURISDICIONAL E AMPLIAÇÃO DO \\ DIREITO DE ACESSO À JUSTIÇA}

\section{Ambiente virtual}

\subsection{Criação e contexto inicial}

No Supremo Tribunal Federal, a existência de ambientes on-line e assíncronos de deliberação já é uma realidade há mais de uma década.

De acordo com o art. 323 do RISTF, "quando não for caso de inadmissibilidade do recurso por outra razão, o(a) Relator(a) ou o Presidente submeterá, por meio eletrônico, aos demais Ministros, cópia de sua manifestação sobre a existência, ou não, de repercussão geral"'.

Esse é o dispositivo que instalou no seio do STF o Plenário Virtual da Repercussão Geral (PV). Essa inovação teve grande importância, visto que a racionalização buscada pela EC n ${ }^{\circ}$ 45/2004 não se viu travada pela necessidade de reunião presencial dos ministros para averiguação da existência de repercussão geral da questão constitucional versada em cada recurso extraordinário que ascende ao $\mathrm{STF}^{29}$

Como se constata, em 2007, foi criado o PV, por meio do qual os ministros deliberam virtualmente sobre a existência de repercussão geral em matéria discutida em recurso extraordinário. A partir de 2010, nesse ambiente, passou-se a permitir também o julgamento do mérito de temas de repercussão geral na hipótese de reafirmação da jurisprudência consolidada do Tribunal (art. 323-A, do RISTF, acrescentado pela ER no 42 ). ${ }^{30}$

Além do PV da Repercussão Geral, foi instituído ainda o Ambiente Virtual, um novo espaço de deliberação colegiada que permite o julgamento eletrônico de mérito de processos, tanto no Plenário quanto nas Turmas. Esse novo espaço de sessões virtuais colegiadas não se confunde com o PV, embora, em ambas as modalidades, os sistemas eletrônicos funcionem 24 horas por dia e o julgamento ocorra de maneira assíncrona, com participação dos ministros de forma remota durante um certo período de tempo.

As sessões virtuais foram criadas em 22/6/2016, sob a Presidência do Ministro Ricardo Lewandowski. Por meio da Emenda Regimental $n^{\circ} 51^{31}$, foram acrescentados dispositivos ao

${ }^{29}$ MIRANDA DE OLIVEIRA, Pedro. Recurso extraordinário e o requisito da repercussão geral. São Paulo: RT, 2013. p. 348.

${ }^{30}$ BRASIL. Supremo Tribunal Federal. Emenda Regimental $\mathbf{n}^{\mathbf{0}}$ 42, de 2 de dezembro de 2010. Altera dispositivos do Regimento Interno do Supremo Tribunal Federal. Disponível em: http://www.stf.jus.br/arquivo/norma/emendaregimental042-2010.pdf. Acesso em: $1^{\circ}$ abr. 2021.

31 BRASIL. Supremo Tribunal Federal. Emenda Regimental $\mathbf{n}^{\circ}$ 51, de 22 de junho de 2016. Acrescenta dispositivos ao Regimento Interno do Supremo Tribunal Federal para permitir o julgamento por meio 
RISTF para permitir que o agravo interno - regimental (art. $317, \S 5^{\circ}$ ) e os embargos de declaração (art. 337, $\S 3^{\circ}$ ) pudessem ser submetidos a julgamento por meio virtual, a critério do relator e observada a competência do órgão colegiado (Plenário ou Turmas). A sua regulamentação inicial coube à Resolução $n^{\circ} 587 / 2016^{32}$ e as primeiras sessões virtuais foram realizadas em 12/8/2016.

De acordo com o estudo empírico produzido no âmbito desta pesquisa, a partir dos dados extraídos da página de estatística do $\mathrm{STF}^{33}$, a referida alteração regimental foi editada no contexto de uma crescente sobrecarga do ambiente presencial de deliberação colegiada com o julgamento de um volume cada vez maior de recursos internos considerados incabíveis ou improcedentes.

No ano de 2015, no ambiente colegiado presencial, o percentual de recursos internos com julgamento favorável foi de 1,13\% (187 decisões), contra 98,87\% desfavoráveis (16.398 decisões). Na linha histórica abaixo (2010-2015), é possível cotejar o percentual de decisões favoráveis e desfavoráveis ao longo do período analisado.

\section{Gráfico 1 - STF: recursos internos (agravos regimentais e embargos de declaração) /}

Percentual por resultado de julgamento / Análise anual: 2010- 2015.

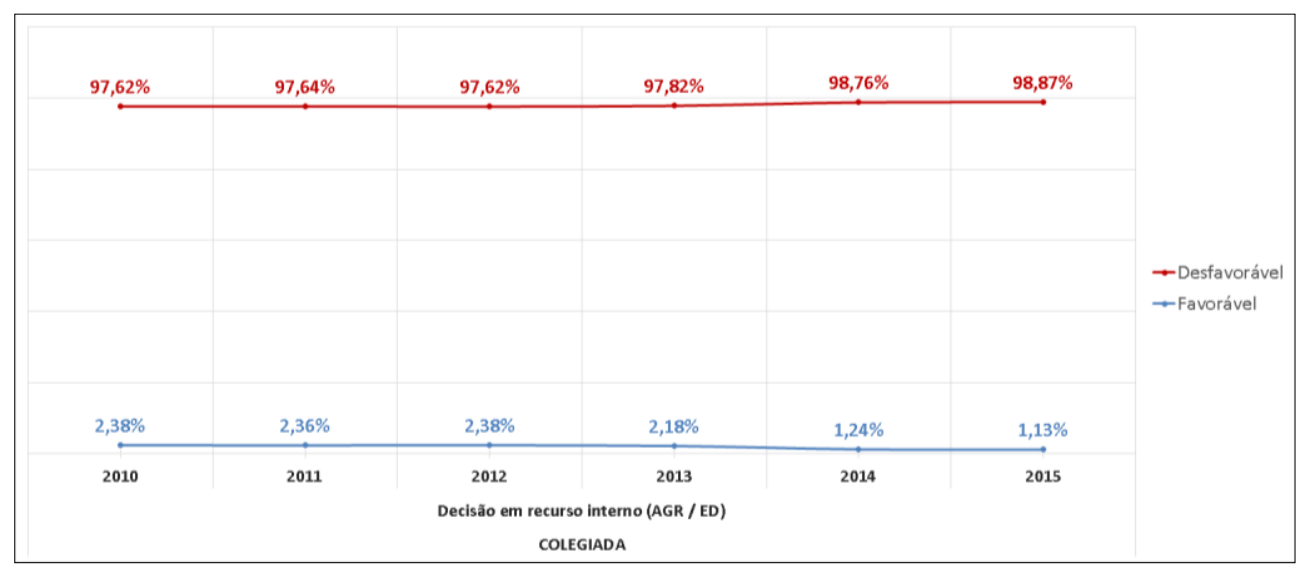

Fonte: Elaborado pelos autores a partir de dados extraídos da página de estatística do STF.

eletrônico de agravos internos e embargos de declaração. Disponível em: http://www.stf.jus.br/arquivo/norma/emendaregimental051-2016.pdf. Acesso em: $1^{\circ}$ abr. 2021.

32 BRASIL. Supremo Tribunal Federal. Resolução $\mathbf{n}^{\circ} \mathbf{5 8 7}$, de 29 de julho de 2016. Dispõe sobre o julgamento em ambiente eletrônico de agravos internos e embargos de declaração no Supremo Tribunal Federal. Disponível em: http://www.stf.jus.br/arquivo/norma/resolucao587-2016.pdf. Acesso em: 6 abr. 2021.

33 Estatística: decisões colegiadas (2010-2020). Supremo Tribunal Federal. 2021. Disponível em: http://stf.jus.br/portal/pauta/pesquisarCalendario.asp. Acesso em: 6 abr. 2021. 


\section{SUPREMO TRIBUNAL FEDERAL NO PERÍODO DA PANDEMIA COVID-19: AMBIENTE VIRTUAL \\ COMO UMA SOLUÇÃO DE EFICIÊNCIA JURISDICIONAL E AMPLIAÇÃO DO \\ DIREITO DE ACESSO À JUSTIÇA}

A partir dessa análise empírica histórica dos dados relativos às decisões em recursos internos, é possível constatar que foi mantida a maior parte das decisões monocráticas submetidas a julgamento colegiado no STF durante o período analisado.

Com efeito, os espaços presenciais de deliberação estavam sendo cada vez mais sobrecarregados com o julgamento de recursos internos que eram, ao final, julgados improcedentes ou incabíveis, em detrimento da utilização desse espaço qualificado de julgamento presencial para a apreciação de temáticas constitucionais que demandassem uma maior discussão em tempo real entre os ministros.

\subsection{Ampliação da competência}

A criação dos ambientes das sessões virtuais (Plenário e Turmas) representou uma inovação normativa e tecnológica que ampliou o potencial de capacidade deliberativa da Corte, de modo que os gabinetes de ministros passaram a dispor tanto do ambiente presencial (síncrono) quanto virtual (assíncrono) para submissão de processos a julgamento colegiado.

Apesar de as sessões virtuais já serem uma realidade no Tribunal, foi o Planejamento Estratégico STF Rumo a 2020 que previu a iniciativa estratégica de ampliar as possibilidades de julgamento em ambiente virtual, como medida prioritária para o biênio 2019/2020, fundada na visão de "ser referência de prestação jurisdicional eficiente, transparente e responsável", conforme Portaria $n^{\circ} 75^{34}$, de 21/3/2019.

Com efeito, passados quase três anos desde a criação do sistema virtualizado, a competência jurisdicional do ambiente foi ampliada por meio da ER $n^{\circ} 52^{35}$ e da Resolução $n^{\circ}$ $642^{36}$, ambas de 14/6/2019. A iniciativa foi uma proposta do Ministro Dias Toffoli, então Presidente.

\footnotetext{
${ }^{34}$ BRASIL. Supremo Tribunal Federal. Portaria n $\mathbf{n}^{\mathbf{7}}$ 75, de 21 de março de 2019. Planejamento Estratégico STF Rumo a 2020 - biênio 2019/2020. Disponível em: http://stf.jus.br/arquivo/norma/portariapr075-2019.pdf. Acesso em: 11 abr. 2021.

${ }^{35}$ BRASIL. Supremo Tribunal Federal. Emenda Regimental $\mathbf{n}^{\mathbf{0}}$ 52, de 14 de junho de 2019. Acrescenta dispositivo ao Regimento Interno do Supremo Tribunal Federal para ampliar as hipóteses de julgamento por meio eletrônico. Disponível em: http://www.stf.jus.br/arquivo/norma/emendaregimental052-2019.pdf. Acesso em: 4 abr. 2021.

${ }^{36}$ BRASIL. Supremo Tribunal Federal. Resolução no 642, de 14 de julho de 2016 - alterada. Dispõe sobre o julgamento de processos em lista nas sessões presenciais e virtuais do Supremo Tribunal Federal. Disponível em: http://www.stf.jus.br/arquivo/cms/noticianoticiastf/anexo/resolucao642alterada.pdf. Acesso em: 4 abr. 2021.
} 
Desse modo, além de agravos regimentais e embargos de declaração passou-se a permitir o julgamento em sessão virtual de medidas cautelares em ações de controle concentrado (ADI, ADC, ADO e ADPF), de referendo de medidas cautelares e de tutelas provisórias e de mérito das demais classes processuais, quando a matéria discutida tivesse jurisprudência dominante na Corte, até mesmo no caso de julgamento de mérito de temas de repercussão geral. De acordo com notícia na página do Tribunal, “o objetivo da ampliação do rol de processos que podem ser analisados em ambiente virtual é otimizar a pauta e assegurar a duração razoável do trâmite ${ }^{, 37}$.

Desde as primeiras sessões (12/8/2016) até o final de 2019, houve um progressivo crescimento de decisões colegiadas proferidas em ambiente virtual, semestre a semestre. No período, foram 41.362 julgamentos. ${ }^{38}$

A partir da ampliação da competência jurisdicional (14/6/2019), foi admitida a apreciação de méritos processuais, tendo sido proferidas 227 decisões no segundo semestre de 2019, sendo as principais: ADI (190), RE objeto de temas de repercussão geral (7) e ADPF (7), que somadas representam mais de $90 \%$ desse total.

No geral, as cinco principais classes processuais apreciadas nesse período (2016 a 2019) foram $\operatorname{ARE}(57,3 \% \mid 23.704), \operatorname{RE}(16,7 \% \mid 6.893), \mathrm{HC}(8,7 \% \mid 3.616), \operatorname{RCL}(5,9 \% \mid 2.446) \mathrm{e}$ MS $(3,3 \% \mid 1.366)$, que correspondem a quase $92 \%$ do total.

\section{Pandemia da Covid-19 e evolução do ambiente virtual}

\subsection{Equiparação da competência: presencial e virtual}

No contexto da pandemia da Covid-19, em 18/3/2020, na $2^{\text {a }}$ Sessão Administrativa do $\mathrm{STF}^{39}$, além de outras medidas, foi aprovada a proposta de $\mathrm{ER} \mathrm{n}^{\mathrm{o}} 53^{40}$, que alterou o art. 21-B do RISTF para dispor que todos os processos de competência do Tribunal podem ser

37 Entenda o que muda com a ampliação dos casos que podem ser julgados em plenário virtual no STF. Supremo Tribunal Federal. Brasília, 10 jul. 2019. Disponível em: http://portal.stf.jus.br/noticias/vernoticiadetalhe.asp?idconteudo=416241\&ori=1. Acesso em: 10 abr. 2021.

38 Esses quantitativos foram calculados pelos autores a partir de dados extraídos da página de estatística do STF.

39 STF mantém realização de sessões presenciais e amplia possibilidades de julgamento por meio virtual. Supremo Tribunal Federal. Brasília, 18 mar. 2020. Disponível em: http://portal.stf.jus.br/noticias/vernoticiadetalhe.asp?idconteudo=439661\&ori=1. Acesso em: 10 abr. 2021.

${ }^{40}$ BRASIL. Supremo Tribunal Federal. Emenda Regimental n⿳0 53, de 18 de março de 2020. Altera dispositivo do Regimento Interno do Supremo Tribunal Federal para ampliar as hipóteses de julgamento por meio eletrônico e prever a realização de sustentação oral em ambiente virtual. Disponível em: http://www.stf.jus.br/arquivo/norma/emendaregimental053-2020.pdf. Acesso em: $1^{\text {o }}$ abr. 2021. 


\section{SUPREMO TRIBUNAL FEDERAL NO PERÍODO DA PANDEMIA COVID-19: AMBIENTE VIRTUAL \\ COMO UMA SOLUÇÃO DE EFICIÊNCIA JURISDICIONAL E AMPLIAÇÃO DO \\ DIREITO DE ACESSO À JUSTIÇA}

submetidos a julgamento em listas de processos em ambiente eletrônico, a critério do relator ou do ministro vistor com a concordância do relator.

Com essa equiparação da competência jurisdicional das sessões virtuais com as presenciais, passou-se a permitir que toda classe e qualquer incidente processual possam ser submetidos a julgamento no ambiente virtual, dispensado o requisito anterior de jurisprudência dominante na Corte. Esse é o modelo atualmente vigente.

A partir de então, o ambiente virtualizado tornou-se um espaço deliberativo de elevada envergadura constitucional, para julgamento de ações de controle concentrado de constitucionalidade (ADI, ADC, ADO e ADPF), mérito de recursos extraordinários submetidos à sistemática da repercussão geral e, até mesmo, Proposta de Súmula Vinculante (PSV), como no caso da PSV n ${ }^{\circ} 132^{41}$, que resultou na aprovação da Súmula Vinculante $n^{\circ}$ 57.

Durante esse período, identificou-se a tendência de crescimento quantitativo de decisões proferidas em ambiente virtual, com crescimento de quase $20 \%$ no segundo semestre de 2020 , ano em que foram proferidas 17.390 decisões colegiadas apenas em ambiente eletrônico.

Com a equiparação e diante do cenário de pandemia, além do crescimento dos julgamentos de agravos regimentais e embargos de declaração, houve a exponencial ampliação dos julgamentos de méritos processuais, saltando de 227 decisões ( $2^{\circ}$ semestre de 2019) para 1.556 no segundo semestre de 2020. É o que se confirma a seguir.

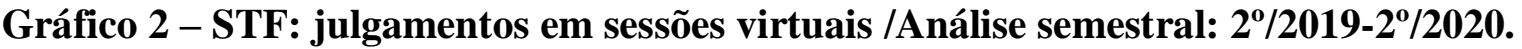

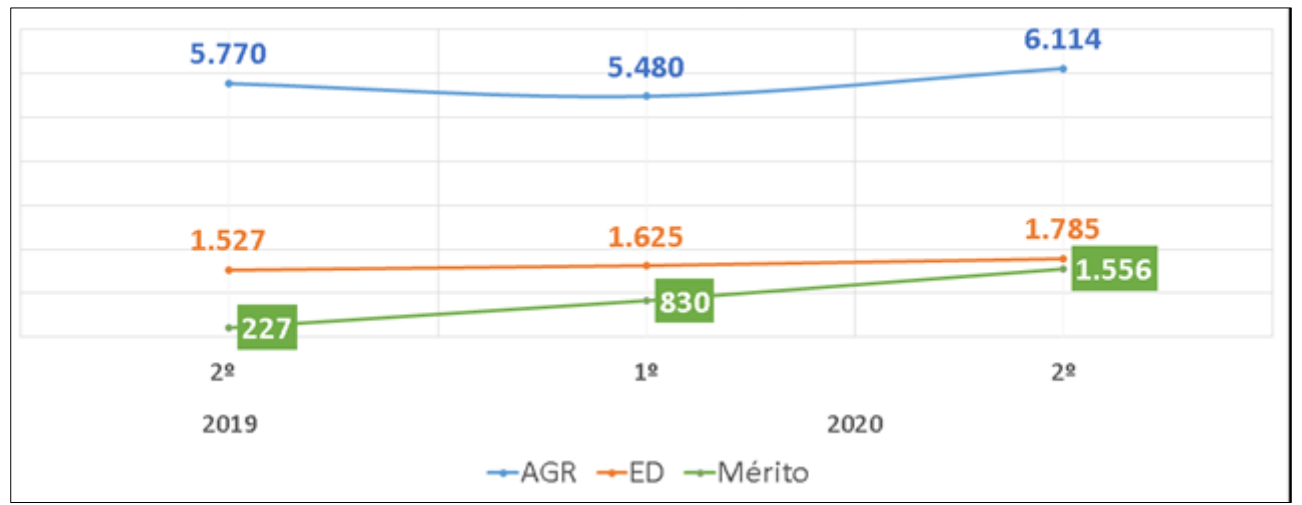

Fonte: Elaborado pelos autores a partir de dados extraídos da página de estatística do STF.

41 BRASIL. Supremo Tribunal Federal. Proposta de Súmula Vinculante $\mathbf{n}^{\mathbf{o}}$ 132. Disponível em: https://portal.stf.jus.br/processos/detalhe.asp?incidente=5534306. Acesso em: 13 abr. 2021. 
Em 2020, no julgamento de agravos internos e embargos de declaração, as quatro principais classes processuais apreciadas foram ARE (42,4\% | 6.356), HC (16,3\% | 2.447), RE $(14,6 \% \mid 2.189)$ e RCL $(12,8 \% \mid 1.924)$, que correspondem a mais de $85 \%$ do total. E, com relação aos julgamentos de mérito, em 2020, somaram-se 2.386 decisões, com predominância de HC (50\%), ADI (17\%) e RHC (10\%).

No que tange à repercussão geral, de um total de 134 temas de mérito julgados em 2020, quase $90 \%$ foram deliberações realizadas em sessões virtuais (112). No total, houve um aumento de $430 \%$ no número de julgamento de temas de repercussão geral em comparação $\operatorname{com} 2019(31) .^{42}$

Em 2020, a combinação das sessões por videoconferência com o novo regime das sessões virtuais possibilitou ao STF um aumento de 2,9\% (18.209) na quantidade de decisões colegiadas proferidas pela Corte em relação a 2019 (17.700), apesar de todos os desafios e dificuldades enfrentados pela Corte em decorrência da pandemia da Covid-19. Do total de decisões colegiadas em 2020, 16.293 foram proferidas em ambiente virtual, o que corresponde a $89,5 \%$ do total. ${ }^{43}$

\section{Gráfico 3 - STF: decisões por ambiente de julgamento (presencial e virtual) em 2020.}

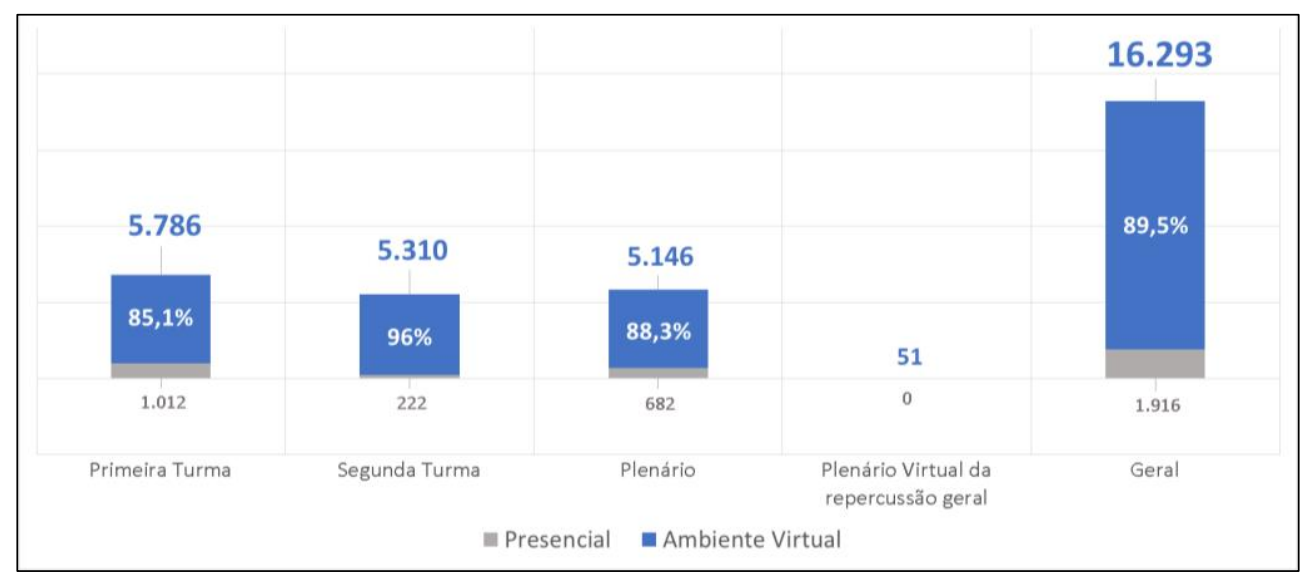

Fonte: Elaborado pelos autores a partir de dados extraídos do Relatório de Atividades STF 2020.

42 BRASIL. Supremo Tribunal Federal. Relatório de atividades 2020. Brasília: Supremo Tribunal Federal, Secretaria de Altos Estudos, Pesquisas e Gestão da Informação, 2021. Disponível em: http://www.stf.jus.br/arquivo/cms/publicacaocatalogoprodutoconteudotextual/anexo/relatorioatividadesstf2020 .pdf. Acesso em: 19 mai. 2021.

43 Ibidem. 


\section{SUPREMO TRIBUNAL FEDERAL NO PERÍODO DA PANDEMIA COVID-19: AMBIENTE VIRTUAL \\ COMO UMA SOLUÇÃO DE EFICIÊNCIA JURISDICIONAL E AMPLIAÇÃO DO \\ DIREITO DE ACESSO À JUSTIÇA}

No ano em análise, ao se olhar apenas o Plenário, 88,3\% das decisões foram tomadas em ambiente virtual, o que contribuiu para um aumento de 48,6\% (5.828) no quantitativo de deliberações em comparação com o ano anterior (3.921).

\subsection{Devido processo legal, transparência e accountability}

Em seu desenho inicial, o ambiente virtualizado do STF foi alvo de reiteradas críticas por parte da doutrina e de instituições públicas e privadas, que alegavam a inconstitucionalidade da modalidade eletrônica de julgamento, por violação a princípios constitucionais e normas processuais relacionadas ao devido processo legal.

As evoluções implementadas no período da pandemia da Covid-19 superaram antigas críticas da doutrina especializada, que apontavam ausência de publicidade, transparência e fundamentação nas decisões.

Como reação às dificuldades e aos desafios apresentados pela crise da pandemia, houve significativa ampliação dos mecanismos de participação nos julgamentos eletrônicos pelos atores da justiça e adoção de soluções de transparência que passaram a possibilitar à sociedade acompanhar publicamente o julgamento de cada processo, por meio de ampla divulgação dos conteúdos e documentos relacionados aos feitos.

Importante contribuição para essa temática foi realizada pelo Informativo $S T F^{44}$, que sistematizou infográficos e demonstrou (i) a evolução do ambiente virtual e (ii) o passo a passo das sessões virtuais.

Nessa publicação, o fluxo da sessão virtualizada foi apresentado na seguinte ordem: (1) inclusão em pauta para julgamento virtual; (2) publicação da pauta e do calendário de julgamento; (3) sustentação oral; (4) relator: inclusão do relatório e voto; (5) início da sessão virtual: votação; (6) questões de fato e memoriais; (7) pedido de vista; (8) destaque para julgamento no ambiente presencial; (9) quórum; (10) ausência de manifestação; (11) placar de votos; e (12) conclusão do julgamento.

Quanto ao primeiro item do fluxo (inclusão em pauta para julgamento virtual), o ministro relator pode submeter a julgamento em sessão no ambiente virtual qualquer classe ou

${ }^{44}$ INFORMATIVO STF. Brasília: Supremo Tribunal Federal, Secretaria de Altos Estudos, Pesquisas e Gestão da Informação, $\quad \mathbf{n}^{\mathbf{0}} \quad \mathbf{1 0 1 1 / 2 0 2 1}$ Disponível em: http://portal.stf.jus.br/textos/verTexto.asp?servico=informativoSTF. Data de divulgação: 9 de abril de 2021. Acesso em: 12 abr. 2021. ISSN: 2675-8210. 
incidente processual, a seu critério. Um importante elemento de eficiência no ambiente virtual é o processo de calendarização, baseado nos valores da previsibilidade e da celeridade.

Nesse ambiente, os relatores têm autonomia para escolher o calendário de julgamento dos processos de maneira concomitante à inclusão do feito em pauta para deliberação. Situação diversa ocorre no ambiente presencial, em que o ministro relator ou revisor inclui o processo em pauta, com pedido de dia para o julgamento e indicação do respectivo colegiado (arts. 21, X, § $3^{\circ}$, e 25, I, do RISTF ${ }^{45}$ ).

Com efeito, o processo fica na dependência de inclusão da pauta em calendário, conforme juízo de oportunidade e conveniência do presidente de cada órgão colegiado (Presidência, Primeira ou Segunda Turma), a quem cabe dirigir os trabalhos e presidir as sessões (art. 13, III, do RISTF).

Como regra, as sessões virtuais têm periodicidade semanal e duração de 6 dias úteis ${ }^{46}$, com início na sexta-feira, à 0h, e término na sexta-feira seguinte, às 23h59. Entre a data da publicação da pauta no Diário de Justiça eletrônico e o início do julgamento, deve ser respeitado o prazo de 5 dias, nos termos Resolução 587/2016 ${ }^{47}$, que dá vigência ao art. 935 do $\mathrm{CPC}^{48}$.

No que se refere ao item 3 do fluxo (sustentação oral), os advogados, procuradores e demais habilitados podem encaminhar sustentação oral $^{49}$, após a publicação da pauta e em até

${ }^{45}$ BRASIL. Supremo Tribunal Federal (STF). Regimento interno do Supremo Tribunal Federal, atualizado até a Emenda Regimental n. 57/2020. Brasília: Supremo Tribunal Federal, Secretaria de Altos Estudos, Pesquisas e Gestão da Informação, 2020. Disponível em: http://www.stf.jus.br/arquivo/cms/legislacaoRegimentoInterno/anexo/RISTF.pdf. Acesso em: 14 abr. 2021: Art. 21: São atribuições do Relator: $\mathrm{x}$ - pedir dia para julgamento dos feitos nos quais estiver habilitado a proferir voto, ou passá-los ao Revisor, com o relatório, se for o caso. $\S 3^{\circ}$ Ao pedir dia para julgamento ou apresentar o feito em mesa, indicará o Relator, nos autos, se o submete ao Plenário ou à Turma, salvo se pela simples designação da classe estiver fixado o órgão competente.

${ }^{46}$ BRASIL. Supremo Tribunal Federal. Resolução $\mathbf{n}^{\mathbf{0}} \mathbf{6 8 4}$, de 21 de maio de 2020. Dá nova redação ao $\S 1^{\circ}$ do art. $2^{\circ}$ da Resolução $n^{\circ}$ 642, de 14 de junho de 2019. Disponível em: http://www.stf.jus.br/arquivo/cms/noticiaNoticiaStf/anexo/Resolucao684.pdf. Acesso em: 14 abr. 2021.

${ }^{4}$ BRASIL. Supremo Tribunal Federal. Resolução no 587, de 29 de julho de 2016. Dispõe sobre o julgamento em ambiente eletrônico de agravos internos e embargos de declaração no Supremo Tribunal Federal. Disponível em: http://www.stf.jus.br/arquivo/norma/resolucao587-2016.pdf. Acesso em: 6 abr. 2021.

${ }^{48}$ BRASIL. Lei $\mathbf{n}^{\mathbf{0}} \mathbf{1 3 . 1 0 5}$ de 16 de março de 2015. Institui o Código de Processo Civil. Disponível em http://www.planalto.gov.br/ccivil_03/_ato2015-2018/2015/lei/113105.htm. Acesso em: 1º abr. 2021.

${ }^{49}$ BRASIL. Supremo Tribunal Federal. Emenda Regimental n⿳ 53, de 18 de março de 2020. Altera dispositivo do Regimento Interno do Supremo Tribunal Federal para ampliar as hipóteses de julgamento por meio eletrônico e prever a realização de sustentação oral em ambiente virtual. Disponível em: http://www.stf.jus.br/arquivo/cms/noticiaNoticiaStf/anexo/Emenda53.pdf; e Resolução no 675, de 22 de abril de 2020. Altera a Resolução $n^{\circ}$ 642, de 14 de junho de 2019, e dá outras providências. Disponível em: http://www.stf.jus.br/arquivo/cms/noticiaNoticiaStf/anexo/Resolucao675.pdf. Acesso em: 13 abr. 2021. 


\section{SUPREMO TRIBUNAL FEDERAL NO PERÍODO DA PANDEMIA COVID-19: AMBIENTE VIRTUAL \\ COMO UMA SOLUÇÃO DE EFICIÊNCIA JURISDICIONAL E AMPLIAÇÃO DO \\ DIREITO DE ACESSO À JUSTIÇA}

48 horas antes do início do julgamento. O envio deve ocorrer até às 23 h59 de terça-feira, no caso das sessões que se iniciam a $0 \mathrm{~h}$ de sexta-feira.

O envio das mídias (vídeo ou áudio) é feito pelo Sistema de Peticionamento Eletrônico, que gera um protocolo de recebimento e registro no andamento processual, com o fim de prestar contas do ato com ampla publicidade. Como medida de governança, os arquivos são disponibilizados imediatamente aos gabinetes dos ministros.

O passo 4 do fluxo (relator: inclusão do relatório e voto) representa a manifestação inaugural do relator do processo, com inclusão do relatório e voto no sistema de votação, que somente pode ocorrer após a apreciação das sustentações orais.

Iniciado o julgamento virtual (item 5 do fluxo - início da sessão virtual: votação), os demais ministros têm até 6 dias úteis para votar. As possibilidades de manifestação são: (i) acompanhar o relator, com ou sem ressalva de entendimento; (ii) divergir do relator; ou (iii) acompanhar a divergência, com ou sem ressalvas. Assim como no Plenário físico, não há qualquer impedimento para que um ministro modifique seu voto até o fim da sessão. Caso um ministro modifique seu voto, a alteração aparecerá em vermelho, indicando novo posicionamento.

Durante a sessão, é facultado aos advogados, procuradores e demais habilitados o envio de esclarecimentos por meio de questões de fato ou memoriais (item 6 do fluxo - questões de fato e memoriais), que serão automaticamente disponibilizados no sistema de votação dos ministros, que recebem um alerta por meio eletrônico.

A participação dos ministros não se restringe à votação. Eles podem também apresentar (i) pedido vista (item 7 do fluxo), com a suspensão da sessão; ou (ii) destaque (item 8 do fluxo), para que o julgamento seja deslocado para o ambiente presencial, com a publicação de nova pauta e pedido de calendário para o julgamento, que será definido a critério do presidente do colegiado (Plenário ou Turmas). Nessa hipótese, há o reinício do julgamento, desconsiderando-se os votos já proferidos no espaço virtualizado.

Destaca-se que as devoluções de vistas de processos cujo julgamento se iniciou em sessão presencial podem ter seu julgamento retomado em ambiente virtual, a critério do ministro vistor e com a concordância do relator. 
Quanto ao quórum (item 9 do fluxo) ${ }^{50}$, não alcançado o mínimo de seis votos no Plenário, ou havendo empate na votação, o julgamento será suspenso e incluído na sessão virtual imediatamente subsequente, a fim de que sejam colhidos os votos dos ministros ausentes. No julgamento de habeas corpus ou de recurso de habeas corpus, na hipótese de empate, será proclamada a decisão mais favorável ao paciente. A declaração de constitucionalidade ou inconstitucionalidade de lei ou ato normativo deverá ser pronunciada por maioria qualificada de seis votos em um mesmo sentido.

Em caso de ausência de manifestação (item 10 do fluxo), o ministro que deixar de se pronunciar no prazo regimental terá sua não participação registrada na ata do julgamento. Se o quórum de votação não for alcançado ou se houver empate ${ }^{51}$ na votação, o julgamento será suspenso e incluído na sessão virtual imediatamente subsequente, a fim de que sejam colhidos os votos dos ministros ausentes. Assim, a presunção de voto ficto (por omissão) foi superada a partir da Resolução no 690/2020 52 .

As partes, os advogados e toda a sociedade podem acompanhar a sessão, online e em tempo real, graças aos aprimoramentos normativos e tecnológicos implementados em abril de $2020^{53}$. A partir de então, o STF passou a disponibilizar em seu sítio eletrônico o Painel de Votação (item 11 do fluxo), dando ampla publicidade à íntegra do relatório e voto do relator, bem como aos demais votos e manifestações dos ministros e advogados.

$\mathrm{O}$ acesso à íntegra dos documentos e ao placar da votação pode ser acompanhado em tempo real, por meio da aba "sessão virtual", disponível na página de acompanhamento processual de cada feito em julgamento.

Por fim, finalizado o julgamento virtual (item 12 do fluxo) e alcançado o quórum regimental, o resultado será computado às $23 \mathrm{~h} 59$ do dia previsto para o término da sessão. A decisão de julgamento será divulgada no andamento processual, e o respectivo acórdão

${ }^{50}$ BRASIL. Supremo Tribunal Federal. Resolução $\mathbf{n}^{\mathbf{0}}$ 690, de 1 de julho de 2020. Altera dispositivo da Resolução $\mathrm{n}^{\mathbf{0}}$ 642, de 14 de junho de 2019. Disponível em: http://www.stf.jus.br/arquivo/cms/noticiaNoticiaStf/anexo/RIResoluo.pdf. Acesso em 15 abr. 2021.

${ }^{51}$ No julgamento de habeas corpus ou de recurso de habeas corpus, proclamar-se-á, na hipótese de empate, a decisão mais favorável ao paciente, nos termos do art. 146, parágrafo único, do Regimento Interno do Supremo Tribunal Federal (art. $2^{\circ}, \S 6^{\circ}$, da Resolução n ${ }^{\circ} 642$, com a redação dada pela Resolução n ${ }^{\circ} 690$.

${ }^{52}$ BRASIL. Supremo Tribunal Federal. Resolução $\mathbf{n}^{\mathbf{0}}$ 690, de 1 de julho de 2020. Altera dispositivo da

Resolução $\mathrm{n}^{\circ}$ 642, de 14 de junho de 2019. Disponível em: http://www.stf.jus.br/arquivo/cms/noticiaNoticiaStf/anexo/RIResoluo.pdf. Acesso em: 15 abr. 2021.

${ }_{53}$ BRASIL. Supremo Tribunal Federal. Resolução n⿳ 675, de 22 de abril de 2020. Altera a Resolução $n^{\circ} 642$, de 14 de junho de 2019, e dá outras providências. Disponível em: http://www.stf.jus.br/arquivo/cms/noticiaNoticiaStf/anexo/Resolucao675.pdf. Acesso em: 13 abr. 2021. 
publicado no Diário da Justiça eletrônico. Tanto as sustentações orais quanto o relatório e os votos dos ministros ficam disponíveis publicamente na aba sessão virtual do acompanhamento processual do portal do STF, desde o início do julgamento até 48 horas úteis após o seu encerramento.

\section{Conclusões}

Conclui-se, de todo o exposto, que o Tribunal promoveu uma efetiva transformação do ambiente virtual durante o período da pandemia da Covid-19.

De um lado, o aprimoramento desse relevante espaço deliberativo promoveu uma maior eficiência da prestação jurisdicional durante a pandemia e contribuiu para a razoável duração do processo, na medida em que esse ambiente viabilizou a pauta e o julgamento célere de um elevado quantitativo de demandas num período curto de tempo.

Em 2020, quase $90 \%$ das decisões colegiadas do Tribunal ocorreram em sessões virtuais, assíncronas, com julgamento de matérias e temáticas de elevada estatura constitucional, como mérito de recursos com repercussão geral reconhecida e referendos e méritos de ações de controle concentrado de constitucionalidade.

De outro lado, foram implementadas soluções de transparência e accountability que aprimoraram o direito de acesso à justiça e reforçaram os princípios decorrentes do devido processo legal, em especial a ampla defesa e o contraditório. Ademais, essas inovações promoveram, como medida de igualdade, o acesso democrático à jurisdição constitucional, antes restrito a profissionais de escritórios localizados em Brasília ou a advogados que representavam partes que tinham condições financeiras de arcar com elevados custos de deslocamento e hospedagem de seus patronos.

Os atores da justiça e advogados de todo o Brasil, mesmo de locais longínquos da Capital Federal, puderam participar efetivamente das sessões colegiadas do Supremo Tribunal Federal, enviar suas sustentações orais e esclarecimentos de questões de fato por meio eletrônico, antes e durante a sessão virtual, com baixo custo e independentemente do local físico de seu domicílio. Foi assegurado, pois, o exercício da ampla defesa e do contraditório, em cumprimento ao art. $5^{\circ}, \mathrm{LV}$, da Constituição Federal.

Entende-se igualmente que há ampla publicidade nos julgamentos virtuais, na medida em que são disponibilizados o inteiro teor dos votos e as manifestações dos ministros durante 
a sessão, em ambiente assíncrono inteiramente público e on-line, ao qual toda a sociedade pode ter acesso para acompanhar os julgamentos.

Igualmente, o requisito constitucional de fundamentação (in abstrato) dos julgamentos é adimplido, uma vez que os votos e as manifestações dos ministros são disponibilizados em ambiente público, à medida que são juntados no sistema de votação (art. 93, IX, da $\mathrm{CF}^{54}$ ).

Todos esses avanços, que se consolidaram no período da pandemia da Covid-19, representam um marco disruptivo no processo de transformação da Suprema Corte em uma Corte digital, com foco no acesso igualitário à justiça por meio da prestação on-line de seus serviços, de modo que servidores, juízes, advogados e demais atores da justiça possam participam da atividade jurisdicional mesmo sem estar presencialmente no espaço físico da Corte $^{55}$.

\section{Referências}

FREIRE, Alexandre. O incidente de resolução de recursos extraordinários repetitivos e as audiências públicas no Supremo Tribunal Federal. In: NERY JUNIOR, Nelson; ARRUDA ALVIM, Teresa; MIRANDA DE OLIVEIRA, Pedro. Aspectos polêmicos dos recursos cíveis e assuntos afins. v. 14. São Paulo: RT, 21-57, 2018.

MIRANDA DE OLIVEIRA, Pedro. Recurso extraordinário e o requisito da repercussão geral. São Paulo: RT, 2013.

SAYEG, Ricardo. Fator CAPH - capitalismo humanista: a dimensão econômica dos direitos humanos. São Paulo: Max Limonad, 2019.

SUSSKIND, Richard. The future of courts. Harvard Law School. Center of the Legal Profession, Vol. 6, Issue 5, July/August 2020.

54 BRASIL. [Constituição (1988)]. Constituição da República Federativa do Brasil de 1988. Brasília: Presidência da [2021]. República, Disponível em: https://www.planalto.gov.br/ccivil_03/constituicao/constituicao.htm. Acesso em: 14 abr. 2021.

55 SUSSKIND, Richard. The Future of Courts. Harvard Law School. Center of the Legal Profession, Vol. 6, Issue 5, July/August 2020. Disponível em: https://thepractice.law.harvard.edu/article/the-future-of-courts/. Acesso em: 9 abr. 2021; e Remote Cours Worldwide. Disponível em: https://remotecourts.org/. Acesso em: 16 abr. 2021. 